\title{
Reform of the Healthcare System in the Republic of Slovenia is Late
}

\author{
Sara Ahlin Doljak, Ph.D. \\ Assist. Prof. at the European Faculty of Law (EVRO-PF), \\ Slovenia and lawyer in Law Firm
}

\begin{abstract}
The purpose of the article is to contribute to the future regulation (de lege ferenda) of the considered area in filling the legal vacuums that Slovenian case law senses and perceives in daily trials. More important, however, is the contribution to the out-of-court resolution of health insurance disputes through all forms of alternative dispute resolution, as this certainly contributes to the resolution of social conflicts in this area. The health care reform and establishment of a system that will encourage users and health care providers must consider public health care as a solidarity system of public financing. Health policy must operate widely and to the benefit of all citizens, not just of an individual provider, which can only be achieved by professionalism, responsibility, and effective control of the Ministry of Health. A good health system means that people have access to good health care where basic services are completed. Before offering a complete care to someone, we must ask ourselves what the complete care really means. A basic public health care system must exist; it is not possible to be without it. Everyone should have access to basic care that enables them to remain healthy and covers potential costs of treatment. For all other services that go beyond the basic care, it is reasonable to let in the market.
\end{abstract}

Keywords: Healthcare reform, healthcare system, health insurance, healthcare policy, Ministry of Health

\section{Introduction}

The healthcare system is linked to the wider social security system and it remains essential to maintain a certain degree of redistribution and solidarity. We must not ignore the danger that the diminishing reliance of people on the universality of health care and health rights can lead to a significant reduction in the willingness or social consensus for redistribution. It is this consensus, however, that prevents market laws to prevail in the field of health care. The need to maintain the delicate balance between social solidarity, equitable access and the interests of free enterprise will continue to be important. Therefore, the healthcare system in the Republic of Slovenia undoubtedly needs changes and improvements in institutional, organisational, and financial terms. Only with data and well considered reform interventions into the social and economic foundations of the system and its organisation and funding the improvements can be made in this area.

In the field of health care, we expect the emphasize on the importance of the role of an individual who will be aware, self-responsible and informed. In this context, we can understand the health reform proposals in our country to reduce sickness benefits for injuries that happen out-of-work and in adrenaline sports, the idea of waiting days before the payment of sick benefits starts, etc. The healthcare sector is increasingly exposed to the economic pressures of cost reduction and efficiency gains. It can be expected that in the future; the focus will be on changing (reducing) the scope of public healthcare rights in the field of healthcare service provision. On the demand side, measures are proposed to limit it in the form of co-payments for medicines and doctor visits, referrals to secondary level and use of sick leave. On the supply side, the increasing importance of public-private partnerships is expected. At the same time, it is crucial to establish a transparent system for all actors involved and to keep the goals and actions the same at the declarative and implementation levels. Only in this way will the individual be able to make more rational decisions regarding health insurance and care. However, we must not forget the appropriate way of regulating and controlling private service and insurance providers. In the future, burdens on an individual will increase, and appropriate mechanisms must be put in place to protect vulnerable groups from disproportionately high costs.

A series of attempts to reform healthcare policy in the Republic of Slovenia and the strategic and design plans and related initiatives failed to significantly change the concept formed already in 1992. Under the leadership of the ruling political option in the Republic of Slovenia, the healthcare policies have since independence followed the pattern of diminishing the role of the state by delegating various tasks to other - old and new - stakeholders in the system.

\section{Reform of the healthcare system is late}

The reform of the healthcare system, which we have been waiting too long, is a very important segment of social life in the field of general socio-economic and political life and justice. 
The healthcare system in the Republic of Slovenia certainly has several positive qualities and can be compared with other European systems according to its development achievements. In recent years, the whole system has not been adjusted to the changed circumstances; therefore, it has come into a retarded position from which there are several exits. I wonder in what way the comprehensive health care for residents can be achieved. The guidance in finding the answer has been the obsolete health legislation, accessibility and quality of healthcare programmes and services, definition of public healthcare service network, responsibility for the management and administration of public healthcare institutions, division of work between different levels, effective control of current and investment spending and quality of implemented services and demarcation between public and private in the healthcare system. The healthcare system represents a complex nature of the challenges faced by doctors, policy makers and other actors involved in the healthcare reforms. The main and competitive challenges are to improve the quality of the health care, maintain and improve the equality and increase the efficiency.

The Slovenian story of reforms of the healthcare financing after the socio-political changes at the end of the 1980s and in early 1990s has some contact points regarding the situation of the health care in other EU countries. 25 years ago, Slovenia introduced a fair and sustainable system of social health insurance. Thus, the stability of the healthcare system was achieved. Compulsory health insurance was introduced, which is characterised by progressiveness and state control of expenditure. To ensure a certain degree of stability of the healthcare system, supplementary health insurance was introduced, which is characterised by regression. The main driver of the current reform in the Republic of Slovenia is the unsustainability of the current combination of funding sources. According to the projections of the current government, the reduction of the share of public financing of the health care will not continue. The financial crisis in 2008 encouraged the Ministry of Health to actively consider that additional resources of optimum financing of the healthcare system will be required. One solution that is being offered based on previous experience is the transfer of certain costs to the expenditure covered by supplementary health insurance. Here, we must be careful and prudent since this could lead to a vicious circle of increased insurance premiums and the consequent abandonment of payments for supplementary health insurance due to (too) high premiums. Additional increase in the scope of direct co-payments is nor socially nor politically acceptable since it can become a too heavy burden for the rapidly increasing older population. In the Republic of Slovenia, the new reform process has been carried out since 2009 but not much has been done so far. We are still looking for the most suitable solutions. The best solution for the Slovenian healthcare system is seen in a mixed public and private healthcare system that would ensure transparency regarding the efficiency and equity. Thus, the healthcare system would become more efficient, which is also expected by the citizens and patients. At the same time, we must not forget the efficient management of all sources of financing.

\section{Suggestions for changes}

Regulations to end the discrimination based on coverage and prices must be introduced, which is based on health risks or existing health problems. Moreover, the insurance plans of the insurance companies are required to measure and report on the state of health of the insured persons. Such reporting will help consumers to choose health plans based on reports and prevent the insurers to be stingy with costly services, such as preventive examinations. Health insurance companies that compete in this way, will add value to the system much more effectively than it could be done by health insurance companies that have a state monopoly. It is true that insurers are not responsible for health, but they provide financial security to policyholders.

The triangle of equity, efficiency and costs has been a subject of discussions and analyses of health economists and political analysts for decades. Equity, efficiency, and costs trigger constant tensions that attack the balance of this triangle of the health policy in any system at any time. Europe's healthcare systems are undergoing a major reform process so that they can cope with changing healthcare demands. As a result of the economic crisis, ageing population, an increase in the incidence of chronic diseases and mortality from various causes, and rising costs of providing care, healthcare systems need to adapt to meet these challenges. Addressing these issues requires a change in the way of providing services through the reform of the healthcare system. One way to achieve this is to strengthen primary health care by promoting cooperation between healthcare sectors. This could potentially contribute to the change by transferring hospital care to facilities closer to people in smaller towns and villages, allowing for greater focus on disease prevention and health promotion.

The improvement of the primary care would reduce costly hospitalisations due to chronic diseases. The healthcare reforms are the key to ensuring that healthcare systems provide affordable quality care that will be effective and economically sustainable. Effective use of financial resources is not possible without focusing on health promotion and disease prevention, the importance of mental health and the need to address health inequalities. 
There is ample evidence that the level of spending on health care is not linear with better health outcomes. As we move towards a holistic approach to human beings and accept that poor health is predominantly determined by social determinants, we must recognise that these determinants are not only the responsibility of the healthcare provider alone, but also include social services, education, housing and the third sector. Most healthcare systems are currently organised along organisational lines, which may inhibit the ability to collaborate across sectors.

Equality in health is linked to inequalities regarding health and health outcomes between different social groups, which could be prevented. It is well known that these inequalities are connected to social situation since the inequalities are often experienced by the most vulnerable people because of their socio-economic situation, environment, and lifestyle. In addition, vulnerable people often face greater difficulties in accessing health care, leading to a deterioration of health outcomes, and strengthening the existing inequalities in health. Fragmented nature of healthcare services and limited coordination with other public services intensify this problem.

To improve equality in health care, integration promoting cooperation between government sectors is important. Local planning enables healthcare systems to consider the needs of the population at the local level and thus most efficiently use the resources to deal with the social determinants of health. Localised planning between health and social care and other sectors also reduces organisational barriers. This establishes a more transparent system, so patients can more smoothly pass through the process of health care and easily access to the services they need. This may help to reach those patients who would otherwise not be able to get through each service. The European Commission advocates integrated practices for reducing the social determinants of health and maintaining better health, which would reduce the dependence of the healthcare system and encourage people to work longer. The WHO defines quality care as a "care that is safe, focused on people, timely, efficient, equitable and integrated". ${ }^{1}$ Non-integrated healthcare systems do not meet these aims, while the application of the principles of integration practice has a greater potential for reorganisation of healthcare systems to become focused on people, improve the social determinants of health and increase accessibility, thereby also increasing the effectiveness.

The high level of solidarity between the healthy and the sick and the young and the elderly is an important value that has been introduced by supplementary health insurance. Changes in healthcare financing should retain solidarity as far as possible, which can only be achieved through high percentage of population being insured. Experience from other EU countries shows that countries have achieved high levels of insurance through supplementary insurance and compulsory contractual insurance. If we do not want a substantial increase in out-of-pocket direct payments, these are the only options. The ways to achieve a high level of insurance are to change the existing supplementary insurance, to create a compulsory contractual insurance along with a reduced supplementary insurance or to replace the supplementary insurance with a compulsory contractual one. Thus, under the new supplementary insurance, the insurance companies would become a partner to the Ministry of Health and healthcare providers.

Vulnerable groups need to be protected, insurance coverage for emerging groups such as the chronically ill elderly needs to be expanded, and these preferences are supported by many healthcare policy arguments. Experience clearly shows that countries can - and regularly do - change the social contract underlying the solidarity in the healthcare sector. In some circumstances, further changes to this basic contract may be part of good governance so that they do not necessarily reflect a breach of their custody role. It is important to ask what is the appropriate new mix of compulsory social and supplementary health insurance in response to fiscal rigour, and to what extent the distribution of specific costs and/or services among different types of insurance coverage could reasonably be altered.

I advocate for the preservation of supplementary health insurance. Supplementary health insurance represents a stable source of financing of the public healthcare system in our country with the potential to increase its extent, which should not be omitted without prior consideration of all consequences. A lot of effort has been put in the establishment of the health insurance system in the Republic of Slovenia; therefore, there should be more technical discussions to maintain, upgrade and improve this system. Most persons liable for co-payments of healthcare services has already concluded supplementary health insurance, which is seen in practice as fulfilled purpose of the supplementary health insurance, i.e. ensuring a minimum level of healthcare services to all residents of the Republic of Slovenia at a reasonable price and under the same conditions. Services offered by the supplementary health insurance can therefore be perceived as the so-called services of public economic interest. Services of public economic interest are defined in the EU competition law as economic activities considered by state authorities as activities of special importance for citizens. Services of public economic interest are different from ordinary services by the fact that they must be provided according to the decision of state authorities even if there is no sufficient demand in the market.

\footnotetext{
${ }^{1}$ WHO global strategy on people-centered and integrated health services, 2015 (e-sources).
} 
If state authorities consider that certain services are in the public interest but the market itself cannot provide them in sufficient extent, they may define measures to meet these needs in the form of services of general interest. ${ }^{2}$

I am convinced that the problems of the health care, patients and policyholders will not be solved by privatization of the public health care. Such solution is not recommended neither by domestic nor foreign experts ${ }^{3}$ and has not been implemented anywhere in the EU. Health is a value that cannot be left to mere functioning of the market. In any case, action is needed to improve the efficiency of the healthcare system in Slovenia and the EU.

The healthcare system in the Republic of Slovenia must be improved and its shortcomings eliminated by deliberate steps, in order not to repeat the mistakes of other countries and reject good solutions that are already included in our healthcare system.

\section{Financing health care}

Financing of the health care in the Republic of Slovenia largely depends on social contributions and labour market changes, which means that the healthcare system depends on the level of employment. When employment is lower, less contribution from salaries are collected. Another problem is rapid ageing of population and lower proportion of active population. More diversified financing sources that will be sustainable and stable are needed in the form of additional general taxes. Contribution rates for pensioners paid by the pension fund are very low and could be complemented by financing from general tax revenue, which would help to stabilise the financing. This is the most probable option for improving the healthcare financing system in Slovenia. I believe that state financing of contributions for children would be useful.

I propose more even burden of compulsory health insurance for all categories of insured persons (currently, some pay relatively more due to low monthly income while the rights are the same for all) and changes in the supplementary insurance. Supplementary insurance is unfair because premiums are the same for all regardless on the amount of revenue. The solution lies in the elimination of regressivity, increase of solidarity in financing, maintenance of high involvement and financial security of the population and the increase of the transparency of the system. The weakness of the supplementary insurance is that the premium is the same regardless of the amount of income, administrative expenses and profits of insurance companies are increasing, the system lacks transparency and better regulation is needed. Analysis of the costs of the healthcare system cannot be done only in theory but it is necessary to visit hospitals, healthcare centres and verify what is happening in healthcare institutions.

External control of operations should be established in public healthcare institutions. To a limited extent, this is currently implemented by the Court of Auditors but not effectively enough. Concessionaires are an important part of the public healthcare system, which complement the public healthcare network where the health care cannot be organised otherwise. The Act Amending the Health Services Act ${ }^{4}$ does not abolish concessions in the health care as it is wrongly and misleadingly interpreted in the public. The granting of concessions must be harmonised with the law on public-private partnership ${ }^{5}$ which has been in force for ten years and has not been considered in the granting of concessions so far. Moreover, the granting of concessions must be harmonised with the Directive 2014/23/EU of the European Parliament and of the Council of 26 February 2014 on granting of concession contracts in the part related to the concessions for health care services. The deadline for the implementation of this Directive expired on 18 April 2016. The granting of concessions must comply with the network of public healthcare services and needs of the citizens and not the needs of doctors. Concessions should be granted only when and where the public healthcare centres and hospitals are not able to meet the needs of the population. I propose for the concessions to be granted through public tenders, for a limited time and according to predetermined criteria and set standards. General public wrongly believes that a concessionaire is a synonym for a private medical practice doctor. There are no legal restrictions on the establishment or registration of a private practice since private doctors depend on self-funding patients while concessionaires are partly financed from public funds and therefore there are rules and controls that apply to them.

In Slovenia, the public health care is the holder of the healthcare services. I oppose the privatisation with competition among insurance companies because this would make healthcare services and, consequently insurance premiums, more expensive. Also, in the Republic of Slovenia, one can access certain healthcare services more quickly by a direct payment. Some private insurance companies market services to "speed up the queues" by which insurance companies cover self-funded services to people who pay extra few Euro per month.

\footnotetext{
${ }^{2}$ Communication from the Commission on services of general interest in Europe (OJ 2001 C17).

${ }^{3}$ according to S. Setnikar-Cankar and V. Petkovšek, 2013, p. 221-234.

${ }^{4}$ Act Amending the Health Services Act (Official Gazette of the Republic of Slovenia, no. 64/17).

${ }^{5}$ Public-Private Partnership Act (Official Gazette of the Republic of Slovenia, no. 127/06). 
Insurance companies are fighting for two million people in the Republic of Slovenia; therefore, they wish to obtain policyholders by marketing and sponsorships.

Each insurance company appears in the market in order to make profit and not due to altruism towards the policyholders. On such a small market as Slovenia, no more than three insurance companies can appear in the market with sufficient profit.

I do not agree with the Health Insurance Institute of Slovenia (HIIS) offering supplementary insurance. The assumption that the HIIS would thus have lower administrative costs, would not generate profits and could have lower premiums is not true. If the HIIS offered supplementary insurance, it should transform its status into an insurance company. For the transformation of status or establishment of an insurance company the required capital adequacy and the minimum initial capital amounts to 3.7 million EUR ${ }^{6}$. An insurance company must have insurance and technical reservations which are invested in bonds, deposits, and shares.

\section{Conclusion}

Upon the adoption of amendments to the legislation in the field of health care, I propose to the Ministry of Health to consider the payment of premiums which would not be subject to the insurance legislation. Contributions or premiums payable according to income would be collected by a fund and would go directly to the healthcare budget with minimal administrative costs. Insurance companies are intermediaries; therefore, too much money is lost for the costs and profits of insurance companies and such a system of supplementary insurance would not work. The Health Insurance Institute of Slovenia should be given more powers when purchasing healthcare services, which should be more strategically, for at least three to five years in advance.

I also do not advocate the abolition of supplementary insurance while raising the premiums of compulsory insurance, since the health fund is already too dependent on contributions from salaries. Upon an increase in unemployment, revenues for the health care are reduced. Supplementary insurance has the advantage that it does not paid only by employed persons but also by pensioners. It is true that the supplementary health insurance should be adjusted to the income capacity of individuals, especially pensioners since the current uniform premium is not the right solution. For some pensioners $33.46^{7}$ EUR, which is the current monthly amount of the supplementary health insurance, means that they pay one monthly pension for supplementary insurance in one year. Those with the lowest pensions and salaries should pay less than they do now.

It would be best to take an amount of the net salary and allocate it directly to the healthcare budget. We are not sufficiently aware that this represents the money for health investment which brings greater well-being, increased productivity, new jobs and growth in the gross domestic product.

The findings of the analysis conducted by the World Health Organization ${ }^{8}$ for the Ministry of Health show that certain areas need systemic changes since the financing of health care is too dependent on contributions from salaries. It is necessary to increase the number of medical teams and improve the integration between healthcare levels to provide a more comprehensive care for the patient. The financing of the healthcare system should be diversified, the share of public resources for health care increased and, foremost, it is necessary to determine whether the existing resources are efficiently spent. Additional resources may be obtained by some other measures, such as more equitable taxation of pensioners, payment of 10 EUR per month into the healthcare budget from the state budget for every child and increase of the excise duties on tobacco, sweet beverages and alcohol. Thereby, it is necessary to consider the ageing of the population in Slovenia and consequently the field of the long-term care and what will the ageing population and decreasing proportion of active population mean for collecting the resources for the health care. I believe that it is necessary to establish a clear and transparent healthcare system so that taxpayers will know where their money goes. The insurance system is now inadequate; in particular, it is essential that the Ministry of Health and the Ministry of Finance and other responsible entities define what is included in the basket obtained by the patient from the existing healthcare system, what exceeds it and how much the patient will pay. Moreover, it is necessary to distinguish and clearly define what is public and what is private healthcare system in the Republic of Slovenia.

\footnotetext{
${ }^{6}$ Paragraph 2 of Article 233 of the Insurance Act (Official Gazette of the Republic of Slovenia, no. 93/15 and 9/19).

${ }^{7}$ WIZ health insurance, (e-source).

${ }^{8}$ S. Thomas... [et al.], 2015, p. 9 (e-source).
} 
We cannot talk about the health care only as the burden of the economy. It is not right to say that we give nine percent ${ }^{9}$ of the GDP for the health care, it would be more correct to say that the health care creates 8.2 percent of the GDP. Therefore, structural reforms are required in Slovenia to increase the stability of the healthcare system.

The increase of the share of the GDP for expenditure on health care and long-term care is expected; but if we do not do anything, we will have to face the most extreme methods to rationalize the demand - these are even longer queues. It is necessary to establish a healthcare system that will operate efficiently, professionally, and independently from everyday politics. Healthcare economy with realistic prices will allow healthy competition between the public and private healthcare providers. The change in the calculation of supplementary health insurance should cover the services that are not covered by the compulsory insurance. The managements of public healthcare institutions need the authorization to outline a vision of operation, responsibly manage the institution and be independent in personnel policy, remuneration and marketing of the healthcare services.

\section{Sources and bibliography}

(ZJZP) Zakon o javno-zasebnempartnerstvu. (Public-Private Partnership Act) Uradni list RS, št. 127/06

(ZZavar-1) Zakon o zavarovalništvu. (Insurance Act )Ur. 1. RS, št. 93/15 in 9/19

(ZZDej-K) Zakon o spremembah in dopolnitvahZakona o zdravstvenidejavnosti. (Act Amending the Health Services Act ) Ur. 1. RS, št. 64/17

Communication from the Commission on services of general interest in Europe (OJ $2001 \mathrm{C} 17$ ).

FINANCIRANJE zdravstvenegavarstva $\mathrm{v}$ Sloveniji (Financing of the healthcare in Slovenia) URL: https://www.stat.si/StatWeb/Field/Index/10/117 22. 2. 2020.

SETNIKAR-CANKAR, Stanka in PETKOVŠEK Veronika, The Health Care System in Slovenia. V: Health Reforms in Central and Eastern Europe: Options, Obstacles, Limited Out- comes / ur. James Warner Bjorkman in JurajNemec. The Hague: Eleven Publishers, 2013, str. 221-234.

THOMAS, Steve... [et al.], Ocenafinanciranjazdravstva, Končnoporočilo, WHO, 2015 URL: http://www.mz.gov.si/ fileadmin/mz.gov.si/pageuploads/Analiza/04022016_porocila_SL/Report_Evaluating_health_financingSlovenia_FINAL_FORMATTED_29_OC 2015_SLO3_ver1.pdf 15.1.2020

WHO global strategy on people-centered and integrated health services. World Health Organisation. 2015. URL: http://apps.who.int/ iris/bitstream/10665/155002/1/WHO_HIS_SDS_2015.6_eng.pdf 29.12. 2019.

WIZ Zdravjezavarovanje. (WIZ health insurance) URL: https://skleni.wiz.si/zdravje?gclid=Cj0KCQiAv8PyBRDMARIsAFo4wK016_JdFfgnvDbV788uNz87Gsz1Pundl-oVWaYVy_gqYSeSjs0Z0kaApBKEALw_wcB 23. 2.

\footnotetext{
${ }^{9}$ Financing of the healthcare in Slovenia, 2011, p. 2 (e-source). 